\title{
Fur-mediated transcriptional and post- transcriptional regulation of FeSOD expression in Escherichia coli
}

\author{
Sarah Dubrac and Danièle Touati
}

\author{
Author for correspondence: Danièle Touati. Tel: +33 1442747 19. Fax: +33 144277667. \\ e-mail: touatida@ccr.jussieu.fr
}

Institut Jacques Monod, CNRS-Universités Paris 6 et Paris 7, 2 place Jussieu, 75251 Paris Cedex 05, France

\begin{abstract}
Fur (ferric uptake regulation protein) activates sodB expression, increasing expression levels by a factor of seven and sodB transcript stability by a factor of three. Post-transcriptional regulation of $\operatorname{sod} B$ was investigated by searching for endoribonucleases that might be involved in sodB mRNA degradation. The activation of SodB expression was significantly reduced if both the RNaseE and RNasellI genes were mutated. This correlated with cleavage at a palindromic sequence located in the $5^{\prime}$ untranslated region of the sodB transcript. An RNAbinding assay showed that Fur did not directly protect the sodB transcript. It was hypothesized that the persistence of Fur-mediated activation of $\operatorname{sod} B$ expression in the RNase double mutant was probably due to an effect at the transcriptional level. Therefore, it was investigated whether Fur had a direct transcriptional effect in vitro. Fur bound the sodB promoter region with low affinity, but it was not able to increase sodB transcription. H-NS-mediated repression of sodB expression, which has been shown to be Fur-dependent, was characterized. No DNA-bending region was identified in the $\operatorname{sod} B$ promoter region. $\mathrm{H}-\mathrm{NS}$ did not interfere with the post-transcriptional effect of Fur. Fur-dependent H-NS and the Fur post-transcriptional effect were not additive. This suggests that Fur and H-NS effects are indirect and may be mediated by a common intermediate.
\end{abstract}

Keywords: superoxide dismutase, H-NS, RNA stability, iron

\section{INTRODUCTION}

Superoxide dismutases (SODs) are ubiquitous enzymes found in nearly all organisms and they play a major role in the multidefence system against oxidative stress (Touati, 1997). They catalyse the dismutation of the superoxide radical $\left(\mathrm{O}_{2}^{--}\right)$to hydrogen peroxide $\left(\mathrm{H}_{2} \mathrm{O}_{2}\right)$ and oxygen $\left(\mathrm{O}_{2}\right) \cdot \mathrm{H}_{2} \mathrm{O}_{2}$ is in turn eliminated by catalases and peroxidases (Fridovich, 1997). Two cytoplasmic SODs have been identified in Escherichia coli, a manganese SOD (MnSOD) and an iron SOD (FeSOD), encoded by $\operatorname{sod} A$ and $\operatorname{sod} B$ respectively.

Oxidative stress is potentiated by iron because iron participates, with $\mathrm{H}_{2} \mathrm{O}_{2}$, in the Fenton reaction, leading to the formation of the very reactive hydroxyl radical, which may react with any cellular macromolecule (Halliwell \& Gutteridge, 1984; Keyer \& Imlay, 1996). Iron acquisition and metabolism are therefore strictly

Abbreviations: Fur, ferric uptake regulation protein; H-NS, histone-like protein; SOD, superoxide dismutase; UTR, untranslated region. regulated and there is increasing evidence for coordination between the regulation of iron homeostasis and defence against oxidative stress (reviewed by Touati, 2000). In particular, synthesis of both the cytoplasmic SODs of E. coli (MnSOD and FeSOD) is controlled by the regulator of iron homeostasis, Fur (ferric uptake regulation protein) (Niederhoffer et al., 1990; Tardat \& Touati, 1991). In turn the expression of fur is regulated by two global regulator systems of oxidative stress, OxyR and SoxRS (Zheng et al., 1999).

Fur, in association with $\mathrm{Fe}(\mathrm{II})$, represses the transcription of genes involved in iron uptake (Bagg \& Neilands, 1987). More generally, it represses the transcription of genes involved in iron metabolism, general metabolism, stress responses, pathogenicity and various other processes (reviewed by Escolar et al., 1999). The molecular mechanism of the transcriptional repression by Fur is well known. The promoters of Fur-repressed genes contain one or two target DNA sequences called iron boxes, displaying various degrees of similarity to the consensus 5'-GATAATGATAATCATTATC-3' 
sequence (de Lorenzo et al., 1987). This sequence was initially characterized as a $19 \mathrm{bp}$ palindromic sequence (Calderwood \& Mekalanos, 1988) and has more recently been described as a combination of three repeats of 5'-NAT(A/T)AT-3' (Escolar et al., 1998). In conditions of iron repletion, Fur associates with Fe(II) and binds as a homodimer to the iron box, rendering the promoter inaccessible to RNA polymerase, thereby inhibiting the initiation of transcription (Escolar et al., 1997). All the genes involved in iron homeostasis are repressed at the transcriptional level by Fur, resulting in a correlation between iron requirements and iron uptake. The sodA promoter contains two iron boxes and $\operatorname{sod} A$ transcription has been shown to be repressed by Fur in an iron-dependent manner (Tardat \& Touati, 1991, 1993).

A few cases of Fur-mediated activation have been reported. Fur activates the expression of $f t n$ and $b f r$ (iron storage), $a c n A$ and fumA (Krebs cycle) and $\operatorname{sod} B$ (FeSOD) (Andrews et al., 1989; Gruer \& Guest, 1994; Niederhoffer et al., 1990). Positive effects of Fur have also been detected by proteome analysis after acid stress (Hall \& Foster, 1996). However, nothing is known about the molecular mechanism underlying these activations. In a previous study on the regulation of $\operatorname{sod} B$ expression as a whole, we showed that Fur induced an increase in $\operatorname{sod} B$ expression by a factor of seven (Dubrac \& Touati, 2000). As demonstrated for Fur-mediated repression, this activation was iron-dependent. The cisacting elements involved in Fur-mediated activation were located in the $5^{\prime}$ untranslated region (UTR) of the $\operatorname{sod} B$ transcript, encompassing a palindromic sequence followed by an AT-rich stretch. The activation appeared to be due, at least partly, to Fur-mediated sodB transcript stabilization. H-NS, a histone-like protein, also regulated $\operatorname{sod} B$ expression in a Fur-dependent manner, repressing $\operatorname{sod} B$ expression in the absence of Fur.

We investigated further the mechanism of Fur-mediated activation of $\operatorname{sodB}$ expression by analysing at the molecular level the transcriptional and post-transcriptional effects of Fur on $\operatorname{sodB}$ expression. Fur acted both at transcriptional and post-transcriptional level. These effects appeared to be indirect since purified Fur could not enhance $\operatorname{sod} B$ transcription nor bind the $\operatorname{sod} B$ transcript in vitro. The previously demonstrated effect of Fur on $\operatorname{sodB}$ mRNA stability was found to depend on an endonucleolytic cleavage and to involve RNaseIII and RNaseE. Fur-dependent effect of H-NS interfered with transcription rate and was not additional to the post-transcriptional effect of Fur.

\section{METHODS}

Bacterial strains, phages and plasmids. All strains are E. coli K-12 derivatives and are listed in Table 1. Basic genetic manipulations were carried out by standard procedures (Miller, 1992). $\Delta$ fur::kan, $\Delta$ fur::cat, hns-1001::Tn5seq1 and $\Delta r n c:$ :kan mutations were introduced by P1 transduction, selecting for antibiotic resistance $100 \%$ associated with the mutation as described previously (Compan \& Touati, 1993). The $\Delta r n c:$ :kan mutant was further verified as accumulating
30S RNA precursors (Babitzke et al., 1993). The $\Phi(\operatorname{sodB}$ lac $Z)_{2}$ and $\Phi(\operatorname{sodB}-l a c Z)_{3}$ fusions were described in a previous publication (Dubrac \& Touati, 2000).

Specific strain construction. The rne131 allele was introduced by cotransduction with $z c e 726:: \operatorname{Tn} 10$ and rne131 mutants were selected from $\mathrm{Tet}^{\mathrm{R}}$ transductants on the basis of their lack of growth on minimal medium containing $0 \cdot 4 \%$ glycerol as sole carbon source at $44^{\circ} \mathrm{C}$ (M. Dreyfus, personal communication). The rne1 (ams1) allele was introduced by cotransduction with $z c f 229:: \operatorname{Tn} 10$ and the rne 1 mutants were selected from $\mathrm{Tet}^{\mathrm{R}}$ transductants by their inability to grow at $42{ }^{\circ} \mathrm{C}$. The $\Delta r n c::$ kan hns $-1001:: \operatorname{Tn} 5$ seq 1 rne 131 mutant was constructed as follows. The $\operatorname{trp} B:: \operatorname{Tn} 10$ mutation was introduced into a hns-1001::Tn5seq1 mutant by P1 transduction. A P1 lysate on the resulting strain was used to cotransduce the hns mutation and $\operatorname{trpB}:: \operatorname{Tn} 10$ into QC2922 (urnc::kan). Transductants were selected for tetracycline resistance and screened for hns mutation on the basis of their ability to grow on minimal medium containing $0.5 \%$ salicin as sole carbon source (Ohta et al., 1999). Tetracycline resistance was eliminated by transduction for $\operatorname{tr} p B^{+}$, selecting for tryptophan prototrophy and hns-1001::Tn5seq1 transductants were selected as described above. The rne131 allele was then introduced by cotransduction with zce::Tn10 and rne131 $\mathrm{Tet}^{\mathrm{R}}$ transductants were selected as described above.

Media, growth conditions and $\beta$-galactosidase assays. Cells were grown in LB medium at $37^{\circ} \mathrm{C}$ with shaking at 200 r.p.m. Antibiotics were added as required: ampicillin $\left(500 \mu \mathrm{g} \mathrm{ml}^{-1}\right)$, kanamycin $\left(40 \mu \mathrm{g} \mathrm{ml}^{-1}\right)$, chloramphenicol $\left(20 \mu \mathrm{g} \mathrm{ml}^{-1}\right)$ or tetracycline $\left(10 \mu \mathrm{g} \mathrm{ml}^{-1}\right)$. $\beta$-Galactosidase assays were performed as described previously (Compan \& Touati, 1993).

In vitro transcription assays. DNA fragments containing the $s o d B_{14}$ promoter sequence $(597 \mathrm{bp}$, from -102 to +495$)$, hisL promoter (388 bp, from -285 to +103 ) and iucA promoter (623 bp, from -133 to +490 ) were amplified by PCR using oligonucleotides sodB5 (5'-CGGGTAATGACCCCAAAAAGAATTCGC-3') and 4218 (5'-GGTCAGCGGAGTACCCGCG-3'), hisL5 (5'-CTGACGCGCTTCGCTGTAGC-3') and hisL3 (5'-CCAGCACACATCGCCTG-3'), iucA-2 (5'-GGCAAGCTTCATAATCAAACAGCTCC-3') and $i u c A-3$ (5'-GTTGCGAAAAAGTGCGTCC-3'), respectively, from pHS1-4, chromosomal DNA and pDT10, respectively. The amplified products were purified and quantified with 33258 Hoechst reagent as described by Cesarone et al. (1979). Transcription reactions were performed as described by Escolar et al. (1997), except that the $\operatorname{sod} B$ template was used at a concentration of $0.8 \mathrm{nM}$ and $0.4 \mathrm{U}$ RNAP (purchased from Boerhinger) was added. Samples were mixed directly with an equal volume of $7 \mathrm{M}$ urea containing tracking dyes and were analysed by electrophoresis in a $6 \%$ polyacrylamide $/ 8 \mathrm{M}$ urea gel. The predicted size of the run-off $\operatorname{sod} B$ transcript thereby generated in vitro was $495 \mathrm{nt}$. A fragment containing the hisL promoter was used as a control in the transcription reaction and to normalize the quantity of product in each lane. The hisL template was added at a concentration of $8 \mathrm{nM}$ to each transcription reaction. The lack of any effect of Fur on expression of a hisL-lacZ fusion was demonstrated before beginning these experiments.

DNA gel mobility shift assays. For competition assays, the iucA promoter fragment was prepared from pDT10 by digestion with BamHI and HindIII, resulting in a $170 \mathrm{bp}$ fragment containing two iron boxes. This fragment was eluted from the gel, dephosphorylated and end-labelled with $[\gamma$ $\left.{ }^{32} \mathrm{P}\right] \mathrm{ATP}$ using kinase (Boerhinger Mannheim). Binding assays were performed in a buffer consisting of $10 \mathrm{mM}$ (BisTris)/ 
Table 1. Bacterial strains and plasmids

\begin{tabular}{|c|c|c|}
\hline Strain or plasmid & Genotype & Source or reference \\
\hline \multicolumn{3}{|l|}{ E. coli strains } \\
\hline MG1655 & $\mathrm{F}^{-} \lambda^{-} r p h-1$ & E. coli Genetic Stock Center \\
\hline IBPC642 & IBPC5321 ams1 $\left(T^{s}\right)$ zcf229:: Tn10 & Hajnsdorf et al. (1994) \\
\hline QC2895 & WJW5 rne131 zce726:: Tn10 & M. Dreyfus, CNRS, Paris, France \\
\hline SK7622 & thyA715 $\Delta r n c:$ :kan & Babitzke et al. (1993) \\
\hline BE1410 & FB8 hns-1001::Tn5seq1 & Laurent-Winter et al. (1997) \\
\hline QC1732 & $\mathrm{F}^{-} \Delta l a c U 169$ rpsL $\Delta$ fur::kan & Compan \& Touati (1993) \\
\hline QC2461 & MG1655 $\Delta l a c(I Z)$ & Dubrac \& Touati (2000) \\
\hline QC2517 & MG1655 recD1901:: Tn10 $\Delta$ fur:: cat & Dubrac \& Touati $(2000)$ \\
\hline QC2558 & QC2461 $\Delta$ fur: :kan & Dubrac \& Touati (2000) \\
\hline QC2597 & QC2461 $\Phi(\operatorname{sodB}-l a c Z)_{2}$ & Dubrac \& Touati (2000) \\
\hline QC2598 & QC2461 $\Phi(\operatorname{sodB}-l a c Z)_{2} \Delta f u r:$ : kan & Dubrac \& Touati $(2000)$ \\
\hline QC2700 & QC2461 $\Phi(\operatorname{sodB}-l a c Z)_{3}$ & Dubrac \& Touati $(2000)$ \\
\hline QC2704 & QC2461 $\Phi(\operatorname{sodB}-\text { lac } Z)_{3} \Delta$ fur: :cat & Dubrac \& Touati $(2000)$ \\
\hline QC2828 & QC2461 $\Delta$ fur::kan(pHS1-8) & This work \\
\hline QC2896 & QC2461 $\Phi(\text { sodB-lacZ })_{2}$ rne131 zce726: : Tn10 & This work \\
\hline QC2897 & QC2461 $\Phi(\text { sodB-lacZ })_{2}$ rne131 zce726: : Tn10 sfur::kan & This work \\
\hline QC2909 & QC2461 $\Phi(\text { sodB-lacZ })_{2}$ rne131 zce726:: Tn10 srnc::kan & This work \\
\hline QC2911 & 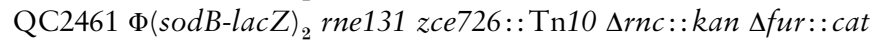 & This work \\
\hline QC2922 & QC2461 $\Phi(\operatorname{sodB}-l a c Z)_{2} \Delta r n c:: k a n$ & This work \\
\hline QC2923 & QC2461 $\Phi(\operatorname{sodB} \text {-lacZ })_{2} \Delta r n c:$ :kan $\Delta$ fur : :cat & This work \\
\hline QC2970 & QC2461 $\Phi(\text { sodB-lacZ })_{2}$ hns-1001:: Tn5seq1 $\Delta$ fur::cat $(\mathrm{pHS} 1-7)$ & This work \\
\hline QC2975 & QC2461 $\Phi(\text { sodB-lacZ })_{2}$ ams-1 rne-ts $\Delta r n c:$ :kan & This work \\
\hline QC2981 & $\begin{array}{l}\text { QC2461 }(\text { (sodB-lacZ })_{2} \text { hns-1001::Tn5seq1 rne131 zce726::Tn10 } \\
\text { srnc::kan }\end{array}$ & This work \\
\hline QC2982 & $\begin{array}{l}\text { QC2461 }(\text { (sodB-lacZ })_{2} \text { hns-1001::Tn5seq1 rne131 zce726: :Tn10 } \\
\Delta r n c:: \text { kan } \Delta \text { fur::cat }\end{array}$ & This work \\
\hline QC6014 & QC2461 $\Phi(\text { sodB-lacZ })_{2}$ ams-1 rne-ts $\Delta r n c:$ :kan $\Delta$ fur::cat & This work \\
\hline \multicolumn{3}{|l|}{ Plasmids } \\
\hline pHS1-4 pHS1-7 pHS1-8 & $\begin{array}{l}\text { pBR322 derivatives carrying DNA fragments of various sizes }(6 \cdot 6 \text {, } \\
10 \cdot 5 \text { and } 3.1 \mathrm{~kb} \text {, respectively) encompassing the } \operatorname{sod} B \text { region }\end{array}$ & Sakamoto \& Touati (1984) \\
\hline pDT10 & pUC19 derivative carrying the inc region & D. Touati \\
\hline
\end{tabular}

borate (pH 7), $40 \mathrm{mM} \mathrm{KCl,} 1 \mathrm{mM} \mathrm{MgCl}, 100 \mu \mathrm{M} \mathrm{MnCl}_{2}$, $2 \mathrm{mM}$ DTT, $5 \%$ glycerol, $5 \mu \mathrm{g}$ sonicated salmon-sperm DNA ml ${ }^{-1}, 100 \mu \mathrm{g}$ bovine serum albumin $\mathrm{ml}^{-1}$ (de Lorenzo et al., 1988), $10 \mathrm{nM}$ purified Fur, $1.5 \times 10^{-3} \mathrm{pmol}$ end-labelled iuc promoter and the indicated amounts of unlabelled DNA. DNA competitor fragments were added to the binding mixture in a final assay volume of $10 \mu \mathrm{l}$. After incubation at $37^{\circ} \mathrm{C}$ for $20 \mathrm{~min}$, samples were run on $4 \%$ polyacrylamide gels polymerized in $40 \mathrm{mM}$ (BisTris)/borate $(\mathrm{pH} 7) / 100 \mu \mathrm{M} \mathrm{MnCl}_{2}$. Blanks with bromophenol blue and xylene cyanol were run in the same gel to visualize the position of the front. Gels were run in the same buffer $[40 \mathrm{mM}$ (BisTris)/borate (pH7)/ $100 \mu \mathrm{M} \mathrm{MnCl}_{2}$ ] at $200 \mathrm{~V}$.

RNA isolation. RNA was isolated at various times after the addition of rifampicin $\left(150 \mu \mathrm{g} \mathrm{ml}^{-1}\right)$ as described by Babst et al. (1996).

Northern blotting analysis. RNA (10-20 $\mu \mathrm{g})$ was subjected to electrophoresis in a $1 \%$ agarose gel. Northern blotting and hybridization (at $42{ }^{\circ} \mathrm{C}$ in $50 \%$ formamide, v/v) were performed essentially as described by Sambrook et al. (1989). An internal sodB fragment, from +306 to +495 , amplified by PCR, was used as probe. The oligonucleotide 5'-ACTACC-
ATCGGCGCTACGGC-3' was used as probe to the $5 \mathrm{~S}$ rRNA to normalize the quantity of RNA in each lane.

RNA gel mobility shift assays. A radiolabelled RNA fragment was generated by in vitro transcription. To obtain a large amount of transcript, the DNA matrix was fused to the T7 promoter. A 172 bp DNA fragment was generated by PCR using the following oligonucleotides: 5'-TAATACGACTCACTATAGGGA*TACGCACAATAAGGC-3' for the $5^{\prime}$ part, in which the bold sequence is the $\mathrm{T} 7$ promoter consensus and the asterisk shows the start site for $\operatorname{sodB}$ transcription, and $5^{\prime}$ CGGGATCCGCCGTAGTGATACTCGATGG-3' for the 3' part. In vitro transcription was performed with $\mathrm{T} 7$ polymerase (Promega), according to the supplier's instructions, with $[\alpha-$ ${ }^{32} \mathrm{P}$ ]UTP to label de novo synthesized RNA specifically. The product obtained was then mixed with $10 \mu \mathrm{g}$ yeast tRNA and $25 \mathrm{U}$ RNasin (Promega) and treated with $1 \mathrm{U}$ RNase-free DNaseI for $15 \mathrm{~min}$ at $37^{\circ} \mathrm{C}$. The RNA was precipitated with 2-propanol and resuspended in DEPC-treated water. To allow folding, the RNA was heated to $85^{\circ} \mathrm{C}$ and cooled slowly to $4{ }^{\circ} \mathrm{C}$ (Alén \& Sonenshein, 1999).

The radiolabelled RNA fragment (about 10000 c.p.m. per reaction) was incubated with purified Fur in $10 \mu \mathrm{l}$ reactions 
containing $10 \mathrm{mM}$ (BisTris)/borate ( $\mathrm{pH} \mathrm{7),} 40 \mathrm{mM} \mathrm{KCl}$, $1 \mathrm{mM} \mathrm{MgCl} 2,100 \mu \mathrm{M} \mathrm{MnCl}_{2}$ or Fe $\left(\mathrm{NH}_{4}\right)_{2}\left(\mathrm{SO}_{4}\right)_{2}, 2 \mathrm{mM}$ DTT and $5 \%$ glycerol, according to the conditions for Fur binding established by de Lorenzo et al. (1988). After incubation at $37^{\circ} \mathrm{C}$ for $20 \mathrm{~min}$, the samples were analysed as described for DNA gel mobility shift assays (see above).

Primer extension reactions. Reverse transcription was carried out at $42{ }^{\circ} \mathrm{C}$ with AMV reverse transcriptase, according to the protocol described by Uzan et al. (1988), using a 25-mer oligonucleotide (5'-CGGGATCCGTAGTGATACTCGATGG-3'), 5' end-labelled, complementary to nucleotides +122 to +146 of the $\operatorname{sodB}$ gene. DNA sequencing was performed with the same primer by the dideoxy chain termination method with the Sequenase kit version 2.0 (USB) and $[\alpha-$ ${ }^{35}$ S]dATP (ICN).

$\left[{ }^{3} \mathrm{H}\right]$ Uridine labelling of RNA. Cells were grown to an $\mathrm{OD}_{600}$ of about 1 in M9 medium containing $0.2 \%$ Casamino acids at $37^{\circ} \mathrm{C}$. $\left[{ }^{3} \mathrm{H}\right]$ Uridine labelling of RNA, chase and precipitations on filters were performed as described by Mudd et al. (1990). The filters were then dried and the radioactivity retained determined by scintillation counting.

\section{RESULTS}

In a previous report, we showed that the expression of a sodB-lacZ transcriptional fusion was activated in a Furdependent manner. This activation was correlated with the Fur-mediated stabilization of the $\operatorname{sod} B$ transcript (Dubrac \& Touati, 2000). Overall, Fur-mediated activation of $\operatorname{sod} B$ expression was significantly stronger (activation factor of seven) than Fur-mediated mRNA stabilization (factor of three to four). Thus RNA stabilization was unlikely to account entirely for the difference in $\operatorname{sodB}$ expression between fur and $\mathrm{fur}^{+}$ strains. We therefore questioned whether Fur could also interfere with $s o d B$ transcription.

\section{Fur effect on sodB transcription}

In a first assay we investigated whether Fur bound to the $\operatorname{sod} B$ promoter region. The capacity of the $\operatorname{sod} B$ promoter to compete in vitro with the inc promoter was tested in gel mobility shift assays. The metal-coordinated Fur bound to the radiolabelled iuc promoter, as shown by de Lorenzo et al. (1988). The shifted Furpiuc complex disappeared with a 10-times molar excess of unlabelled iuc promoter as competitor, whereas a 500-times molar excess of $\operatorname{sodB}$ promoter was required to obtain the same effect (Fig. 1). However, a 500-times molar excess of a non-specific DNA fragment did not act as a competitor. Considering the affinity of the iuc promoter for Fur, i.e. about 5 nM (Wee et al., 1988), we can deduce that the $\operatorname{sod} B$ promoter has an affinity of about $250 \mathrm{nM}$ for Fur. Thus, in vitro, Fur bound to the sodB promoter specifically, but with very low affinity.

We investigated the relevance in vivo of this low-affinity binding in vitro using the FURTA test (Stojiljkovic et al., 1994). The $\operatorname{sodB}$ promoter carried on a high-copynumber plasmid (pUC19 derivative) did not titrate Fur, as shown by the lack of derepression of a fhuF-lacZ fusion (data not shown). This failure of psodB to titrate

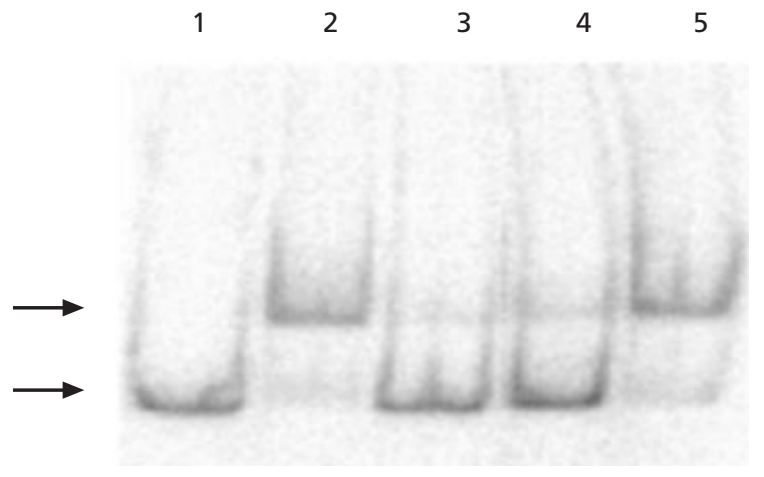

Fig. 1. Competition of psodB with piucA for Fur binding analysed by gel mobility shift assay. ${ }^{32} \mathrm{P}$ end-labelled iucA promoter fragment $(1.5 \mathrm{fmol})$ with no addition (lane 1) or $10 \mathrm{nM}$ Fur (lanes 2-5). A sodB promoter fragment (190 bp), an iucA promoter fragment (170 bp) or a fragment of the sod $B$ structural gene (190 bp) were used as competitors of Fur binding: lane 2, no competitor; $3,15 \mathrm{fmol}$ iucA promoter fragment; 4, $750 \mathrm{fmol}$ sod $B$ promoter fragment; $5,750 \mathrm{fmol}$ sod $B$ gene fragment. The arrows indicate the positions of free iucA fragment (bottom) and of the specific iucA fragment/Fur complex (top).

Fur called into question the biological significance of the observed in vitro binding. However, because of the large number (5000 to 10000) of Fur molecules in the cell (for review see Hantke, 2001) the sensitivity of the FURTA test is not necessarily accurate for a weak promoter. Indeed despite significant Fur titration by the iuc promoter, we observed no significant titration of Fur by the sodA promoter (data not shown), although Fur binding has been clearly demonstrated in vitro (Tardat \& Touati, 1993).

It is interesting to note the presence on the target sequence of $\operatorname{sodB}$ (Dubrac \& Touati, 2000) of an array, ATAAT, preceded by a similar degenerate array. Repeats of such arrays have been shown to be involved in interaction with Fur; however, two repeats were not sufficient for stable binding (Escolar et al., 1998).

We further analysed the effect of Fur on the in vitro transcription of $s o d B$. No increase in transcription rate was observed in the presence of Fur (Fig. 2) whereas, under the same assay conditions, Fur fully repressed iuc transcription (data not shown). To normalize the assay, we used as an internal control of in vitro transcription a DNA fragment constitutively expressing a transcript similar in size to that studied; hisL and thrS were used alternately (Fig. 2). Unexpectedly, the relative efficiencies of transcription from psodB and phisL were very different. The efficiency of in vivo transcription from phisL was similar to that from psodB, as shown by expression of a hisL-lacZ transcriptional fusion (data not shown). However, in vitro, a 10-times molar excess of hisL over $s o d B$ DNA was required to detect a hisL transcript with about the same intensity (Fig. 2). Increasing the concentration of RNA polymerase by a factor of four had no effect (data not shown). However, 


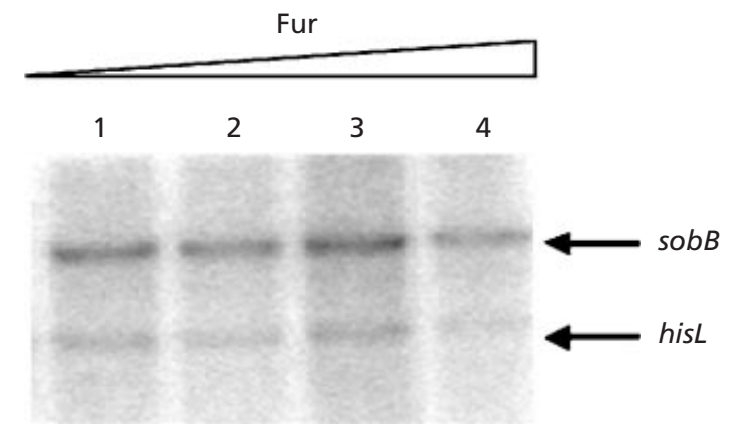

Fig. 2. Effect of Fur on the in vitro transcription of $\operatorname{sod} B$. A $597 \mathrm{bp}$ linear $\operatorname{sod} B$ template $(-102$ to +495$)$ was incubated at $37{ }^{\circ} \mathrm{C}$ with purified Fur at various concentrations in a buffer containing $50 \mu \mathrm{M} \mathrm{MnCl}$. After 5 min, E. coli RNA polymerase and NTPs were added. The reaction mixture was incubated for $20 \mathrm{~min}$ and then analysed on a denaturing polyacrylamide gel. A hisL DNA template $(-285$ to +103) was added, together with $\operatorname{sod} B$ template, to each reaction mixture to control the quality of the reaction and to normalize the quantity of product in each lane. Lanes: 1, no Fur; 2, 200 nM Fur; 3, 400 nM Fur; 4, $800 \mathrm{nM}$ Fur. Positions of transcripts are indicated. The report levels of $\operatorname{sod} B$ transcript as a percentage of hisL are: lane $1,158 \% ; 2,163 \% ; 3,147 \% ; 4,130 \%$. Template amounts: $\operatorname{sod} B, 0.8 \mathrm{nM}$; hisL, $8 \mathrm{nM}$ (ratio sodB DNA/hisL DNA, 1/10).

if the hisL DNA was used alone in the assay, transcription efficiency reached the expected value (data not shown). A similar result was obtained with $t h r S$ (data not shown). This discrepancy between the relative efficiency of transcription in vivo and in vitro indicates that RNA polymerase has a very strong affinity for the $\operatorname{sodB}$ promoter in vitro. This is consistent with there being a factor inhibiting psodB transcription present in vivo but absent in the in vitro assay.

From those results, we concluded that Fur might not directly regulate $\operatorname{sod} B$ at the transcriptional level.

\section{Post-transcriptional Fur-mediated regulation of $\operatorname{sod} B$}

The effect of Fur on $s o d B$ mRNA decay may be a general RNA stabilization effect mediated by an indirect effect of Fur on some RNases. We therefore tested whether Fur stabilized the majority of E. coli mRNAs. The halflife of bulk mRNA was about $3 \mathrm{~min}$ in the parental $\mathrm{fur}^{+}$ strain and $2.7 \mathrm{~min}$ in the fur strain (data not shown). These values are similar to those previously reported for a wild-type strain (2-3 min) (Mudd et al., 1990). Thus, Fur has no effect on the chemical half-life of total mRNA and the effect on the $\operatorname{sodB}$ transcript is specific.

Effect of mutations in major endoribonucleases on the expression of a sodB-lacZ fusion. The cis elements involved in Fur-mediated protection of mRNA transcript were located in the $5^{\prime}$ UTR of the transcript, excluding a possible initial role of $3^{\prime}$-dependent exonucleases, the only exonucleases known to be present in E. coli. A single mutation in the rnc gene, which encodes RNaseIII, an endoribonuclease that cleaves specific doublestranded RNA structures, had no effect on expression of the fusion or on Fur-dependent activation (Fig. 3a). The rne131 mutation in the gene of RNaseE, a single-strandspecific endoribonuclease, did not significantly affect sodB expression either (Fig. 3b). The rne131 allele encodes a truncated RNaseE lacking the C-terminal part of the protein, preventing the association of RNaseE with the degradosome, but without modifying its rRNA processing activity (Lopez et al., 1999). Similarly, the rne1 mutation, which renders $\mathrm{RNaseE}$ catalytic activity heat-sensitive, had no effect (data not shown).

Although neither the rne131 nor the rnc: : kan mutations affect expression of the sodB-lacZ fusion, expression was significantly higher (three times) in a fur strain in which both RNase genes were mutated. A slightly higher level of expression was also observed in the fur $^{+}$strain (1.2 times) (see Fig. 3c). This suggests that
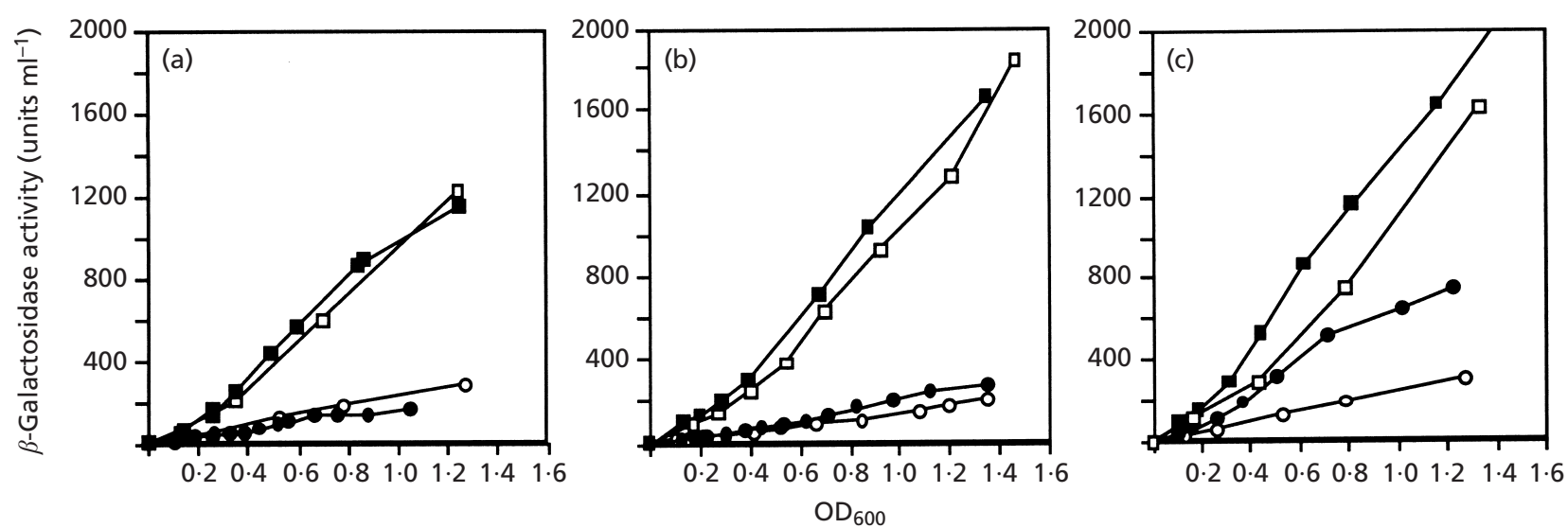

Fig. 3. Effects of various combinations of mutations on expression of a sodB-lacZ transcriptional fusion. Strains were grown in LB medium and assayed for $\beta$-galactosidase activity, expressed in units $\mathrm{ml}^{-1}$, as described in Methods. The values shown are means of three experiments and individual values did not differ by more than $15 \%$ from the means. $\square$, QC2597 (wild-type); O, QC2598 (fur mutant). (a) a, QC2922 (rnc mutant); O, QC2923 (fur rnc mutant). (b) ם, QC2896 (rne131 mutant); O, QC2897 (fur rne131 mutant). (c) Q, QC2909 (rnc rne131 mutant); 0, QC2911 (fur rnc rne131 mutant). 
(a)

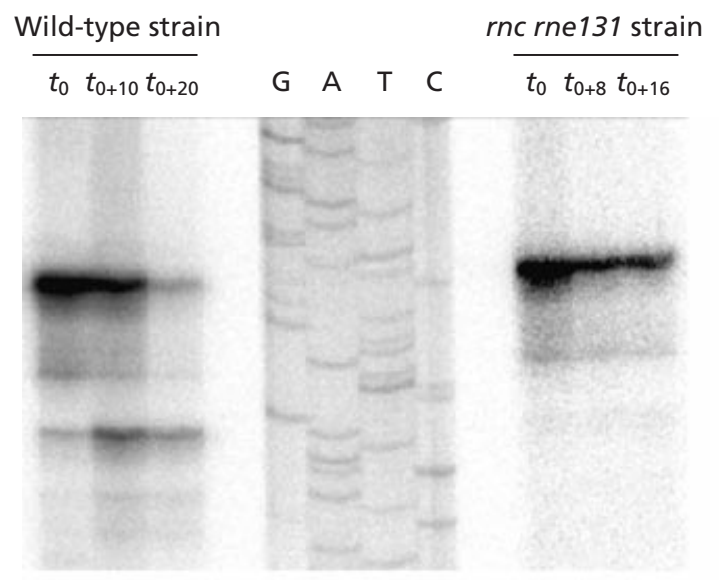

(c)

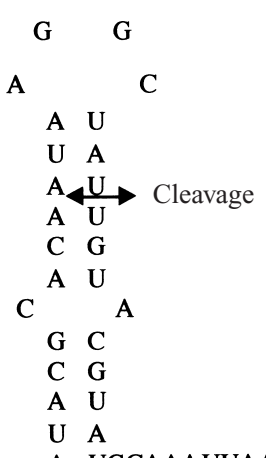

5 ,
A UgCAAAUUAAUAAUAAAggagaguagCAAUG... ${ }_{3}$, (b)

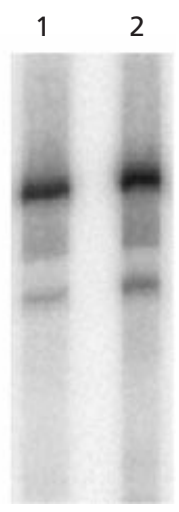

Fig. 4. Site of endonucleolytic cleavage in the $\operatorname{sod} B$ promoter region. (a) Primer extensions performed with RNA from the wild-type (QC2597) and rnc rne131 (QC2909) strains grown to an $O_{600}$ of about 1 at $37{ }^{\circ} \mathrm{C}$. RNA was extracted at various times after the addition of rifampicin. The ${ }^{32} \mathrm{p}$ labelled oligonucleotide used for primer extension was also used for sequencing reactions in lanes G, A, T and C. (b) Primer extensions performed with RNA from the rnc rne1 (QC2975; lane 1) and wild-type (QC2597; lane 2) strains grown at a nonpermissive temperature $\left(42^{\circ} \mathrm{C}\right)$. These results are representative of those obtained in four independent experiments. (c) Cleavage site in the $5^{\prime}$ UTR of the $\operatorname{sod} B$ transcript. Bold characters represent the ribosome-binding site and the start site of translation. endoribonucleases act on the $\operatorname{sod} B$ transcript interfering with $\operatorname{sod} B$ expression. However, as stated above, RNaseIII and RNaseE are specific for different sequences or structures and this synergic effect of the double mutation is difficult to explain by classical models.

Location of an endonucleolytic cleavage involved in the Furmediated stabilization of the $\operatorname{sod} B$ transcript. To identify the possible site of endonucleolytic cleavage responsible for the higher level of $\operatorname{sodB}$ mRNA decay in the fur strain, we examined the $5^{\prime}$ part of the $s o d B$ transcript by primer extension analysis in strains with mutations in genes encoding proteins with various endoribonucleolytic activities. A sodB transcript species shorter than the full-length transcript was identified in the wild-type strain. Cleavage occurred in the palindromic sequence located just downstream from the transcription start site (see Fig. 4). The band corresponding to the cleaved transcript was detected if primer extension was performed on RNA from a wild-type strain or from single rnc and rne131 mutants (Fig. 4a and data not shown), but not if RNA from the rnc rne131 strain was used (Fig. 4a). Cleavage was also detected in a fur strain but the processed transcript was more labile, suggesting greater sensitivity to further degradation (data not shown). Thus both the activity of RNaseIII and the integrity of the carboxy-terminal part of RNaseE must be disrupted to prevent this cleavage.

Different results were obtained with the rne1 mutation of the rne gene which renders the enzyme heat-sensitive. Cleavage was observed in an rnc rne 1 strain at nonpermissive temperature (Fig. 4b). The expression of the sodB-lacZ fusion in a fur rnc rne 1 strain was the same at 30, 42 (Fig. 5b) and $37^{\circ} \mathrm{C}$ (not shown), similar to expression in fur (Fig. 5a). This is consistent with cleavage being important for the RNA processing enhanced in a fur background. Noteworthy is the fact that the effect of activation by Fur of $\operatorname{sod} B$ expression in the wild-type background was temperature-dependent, being reduced at $30^{\circ} \mathrm{C}$ (see Fig. 5a). This is presumably due to a temperature-dependent structural change.

The result obtained with RNA from the rnc rne131 strain was connected with the Fur effect on a sodB-lacZ fusion, $\Phi(\operatorname{sod} B-l a c Z)_{3}$, in which the promoter region is partially deleted, the deletion including the cleavage site identified above. The $\Phi(\operatorname{sodB}-l a c Z)_{3}$ fusion was more strongly expressed than a fusion involving the $\operatorname{sod} B$ wild-type promoter region, $\Phi\left(\operatorname{sodB}-\text { lac } Z_{2}\right)_{2}$. The increase in expression was weak in $\mathrm{fur}^{+}$and significantly higher in fur mutant strains (Dubrac \& Touati, 2000). The introduction of rnc rne131 mutations did not affect the expression of the $\Phi(\operatorname{sodB} \text {-lac } Z)_{3}$ fusion in either $\mathrm{fur}^{+}$or fur strains (Fig. 5c). Thus deletion of the cleavage site appears to mimic effect of the rnc rne131 mutations.

These results together strongly suggest that cleavage occurs within the palindromic sequence located at the $5^{\prime}$ end of the $\operatorname{sod} B$ transcript and that this cleavage is 

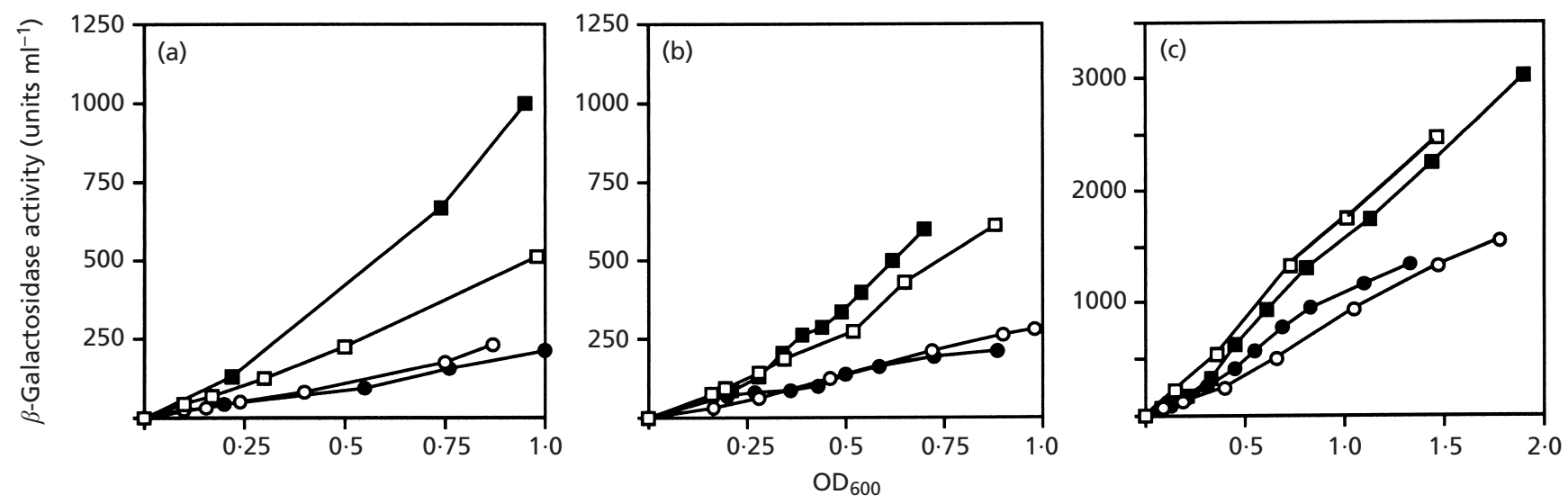

Fig. 5. Expression of sodB-lacZ transcriptional fusions with and without $5^{\prime}$ UTR cleavage of the sod $B$ transcript. Strains were grown in LB medium and assayed for $\beta$-galactosidase activity (expressed in units $\mathrm{ml}^{-1}$ ) as described in Methods. The values shown are means of three experiments and individual values did not differ by more than $15 \%$ from the means. (a, b) Effect of rne1 rnc mutations on the expression of sodB-lacZ transcriptional fusion at various temperatures. (a) $\square$, QC2597 (wild-type) at $30^{\circ} \mathrm{C}$; $\mathrm{O}, \mathrm{QC2598}$ (fur mutant) at $30^{\circ} \mathrm{C}$;, QC2597 at $42{ }^{\circ} \mathrm{C} ; 0$, QC2598 at $42{ }^{\circ} \mathrm{C}$. (b) $\square$, QC2975 (rnc rne1 mutant) at $30^{\circ} \mathrm{C}$; O, QC6014 (rnc rne1 fur mutant) at $30^{\circ} \mathrm{C} ; \mathbf{\square}, \mathrm{QC2} 275$ at $42{ }^{\circ} \mathrm{C}$; $9, \mathrm{QC} 6014$ at $42{ }^{\circ} \mathrm{C}$. (c) Measurement of $\beta$-galactosidase activity of strains carrying the $\Phi(\operatorname{sod} B \text {-lacZ })_{3}$ fusion. The palindromic region shown in Fig. 4 is truncated in $\Phi(\operatorname{sod} B-l a c Z)_{3}$. The sequence $5^{\prime}-C A A T A A G G C T A T T G T-3$ ' is replaced by 5'-ATCCT-3'. This modification results in the absence of the cleavage site. $\square$, QC2700 (wild-type); O, QC2704 (fur); Q, QC2909 (rne131 rnc); Q, QC2911 (fur rne131 rnc).

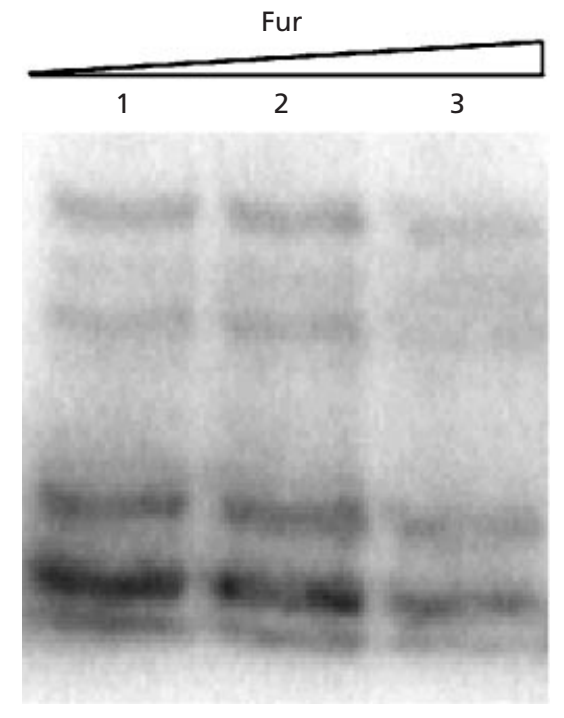

Fig. 6. Effect of Fur on gel mobility shift of the $\operatorname{sod} B$ transcript. The $\operatorname{sod} B$ transcript was prepared by in vitro transcription using $\left[{ }^{3} \mathrm{H}\right]$ uridine. It was then heated at $85^{\circ} \mathrm{C}$ for $10 \mathrm{~min}$ and slowly cooled. About 10000 c.p.m. of radiolabelled mRNA was mixed with purified Fur. Lanes: 1, no Fur; 2, 100 nM Fur; 3, 300 nM Fur.

correlated with the Fur-dependent activation of $\operatorname{sodB}$ expression.

As Fur mediates stabilization of the $\operatorname{sod} B$ transcript, we investigated whether Fur protected RNA from degradation by direct binding. sodB RNA was heated and then cooled slowly to allow multiple possible folding. Purified Fur (at concentrations up to $300 \mathrm{nM}$ ) did not bind any of the refolded forms of RNA (Fig. 6). The binding assays were performed with manganese as the Fur cofactor because this metal is more stable than iron in its reduced form in aerobiosis. An experiment performed with $\mathrm{Fe}(\mathrm{II}) \quad\left[\mathrm{Fe}\left(\mathrm{SO}_{4}\right)_{2}\left(\mathrm{NH}_{4}\right)_{2}\right]$ as the Fur cofactor gave identical results (not shown).

\section{H-NS-mediated repression of the $\operatorname{sod} B$ expression}

H-NS reduced the level of expression of a $\operatorname{sodB}-\mathrm{lacZ}$ transcriptional fusion if the fur locus was inactivated (Dubrac \& Touati, 2000). To determine the level at which H-NS-mediated regulation occurred, we investigated whether H-NS modulated sodB mRNA degradation. As expected, given that the expression of $\operatorname{sodB}$ lac Z was H-NS-independent in the $\mathrm{fur}^{+}$strain, similar amounts of $\operatorname{sod} B$ transcript were detected in the wildtype and the hns mutant. In an hns fur double mutant, the half-life of the $\operatorname{sodB}$ transcript was similar to that in a single fur mutant (data not shown). This result strongly suggests that the observed effect of the hns mutation on sodB-lacZ expression in a fur background was transcriptional.

$\mathrm{H}-\mathrm{NS}$ is known to bind specifically to curved DNA and thereby modulates transcription (Yamada et al., 1991). A computer analysis was performed to identify possible sections of curved DNA in the $\operatorname{sodB}$ promoter region. The bending model was created with the 3D-WEDGE program (G. Micheli, Centro Acidi Nucleici CNR, Rome, Italy). A 1000 bp DNA fragment $(-500$ to +500 from the translation start site) was tested. The cis elements of the $\operatorname{sodB}$ promoter region involved in H-NSmediated regulation are located in the $60 \mathrm{bp}$ region between the transcription start site and the translation start site (Dubrac \& Touati, 2000). Computer analysis showed no potential curvature in the region of the $\operatorname{sod} B$ 
promoter involved in H-NS repression (data not shown). To confirm this prediction experimentally, we analysed the migration of a PCR-amplified fragment of the $\operatorname{sodB}$ promoter containing the region of interest with respect to $\mathrm{H}-\mathrm{NS}$ repression. Migration in agarose at 4 and $60{ }^{\circ} \mathrm{C}$ increased and reduced, respectively, the effect of DNA bending on electrophoretic mobility (Dieckmann \& Wang, 1985). We observed no differential migration at the two different temperatures (data not shown). In the light of previous studies showing a very high specificity of H-NS binding for curved DNA, these results strongly suggest that the observed repression of sodB-lacZ expression by H-NS did not result from binding of $\mathrm{H}-$ NS to the $\operatorname{sodB}$ promoter.

As H-NS repressed expression by a factor of about two, the lower level of expression in the fur strain may have resulted from cumulative effects: loss of RNA stabilization and transcriptional repression via H-NS. Consistent with this, it was predicted that expression of the sodB-lacZ fusion in a strain carrying the fur rne131 rnc hns mutations would reach levels about twice those in the fur rne131 rnc strain, and similar to those in the $\mathrm{fur}^{+}$strain. No difference was found between the two strains, ruling out a cumulative Fur-dependent effect of RNases and H-NS mutations (data not shown).

This supported the view that the Fur H-NS-mediated effect is indirect and that Fur acts indirectly both at posttranscriptional and transcriptional levels.

\section{DISCUSSION}

Fur, which is primarily involved in the regulation of iron metabolism, is now known to regulate a large number of genes. The molecular mechanism of regulation has been studied only for Fur acting as a transcriptional repressor. There are a few reports of positive effects of Fur on gene expression, but the underlying mechanisms were never investigated. It is therefore unknown whether the activation of expression was due to a direct effect of Fur or mediated by an intermediate regulator under Fur control. Our previous study on positive Fur-mediated regulation of the $\operatorname{sodB}$ gene encoding FeSOD suggested that regulation occurred at both the post-transcriptional and transcriptional levels. The data presented here show only a weak binding of Fur to the $s o d B$ promoter region and no binding to the $\operatorname{sod} B$ transcript. Although these data do not authorize us to exclude the possibility that Fur activation of $\operatorname{sodB}$ expression is mediated via a direct binding of Fur on the $\operatorname{sodB}$ promoter, we favour the hypothesis of indirect regulation. (i) The target region of the Fur effect is located downstream from the transcription start site of $\operatorname{sodB}$, a position more frequently subjected to negative than to positive transcriptional control. (ii) Although DNA-binding assays indicated some specific binding of Fur to the promoter region of $\operatorname{sod} B$, binding efficiency was very low and possibly not significant in vivo. (iii) The inability of purified Fur to activate in vitro transcription and the much higher level of in vitro transcription from $\mathrm{psodB}$ than from phisL, despite similar levels of in vivo expression, provide further evidence of an indirect effect and suggest that an inhibitory factor may be missing in the in vitro experiment. (iv) No binding of Fur to RNA was detected, ruling out the hypothesis that Fur acts as an RNA-binding protein. This led us to speculate that an intermediate regulator under Fur control might exist. As the basic level of $s o d B$ expression in the fur mutant is high enough, classical methods of selecting mutants for this putative regulator were not possible. An approach involving transcriptome analysis is currently being used.

One clear consequence of Fur regulation was stabilization of the $\operatorname{sodB}$ transcript. The higher level of $\operatorname{sodB}$ expression in a fur strain in which both major RNase genes were mutated, together with the lack of endonucleolytic cleavage of the $\operatorname{sodB}$ transcript in an rne131 rnc strain, suggested that both RNaseE and RNaseIII were involved in $\operatorname{sodB} \mathrm{mRNA}$ decay. However, the process of RNA degradation is still unclear. In particular, it is not easy to account for the apparent redundancy between the actions of RNaseIII and RNaseE on the $s o d B$ transcript. Cleavage within the palindromic sequence at the $5^{\prime}$ end of the transcript occurs if one of these RNases is present. There is no known example of cleavage at the same site by these two RNases and it has been clearly demonstrated that whereas RNaseIII is double-strand-specific, RNaseE can cleave in single-stranded AU-rich RNA in a $5^{\prime}$-dependent manner (Mackie, 1998; Nicholson, 1999). This suggests that the $\operatorname{sodB}$ transcript is degraded in several steps, including, at the late stage, events dependent on the actions of RNaseIII and RNaseE. Cleavage within the palindromic sequence may be a crucial initial event. RNaseE is an endonucleolytic enzyme involved in mRNA decay and rRNA maturation. It is the central element of the degradosome, a multienzyme complex involved in the decay of most mRNA species. The effect of RNaseE was found only in experiments carried out with the rne131 allele, which was originally characterized in the laboratory of M. Dreyfus (Lopez et al., 1999). This mutant produces an RNaseE truncated at the carboxy-terminal end, resulting in inhibition of the formation of the degradosome without the abolition of catalytic activity. Thus, the rne 131 mutation permits the further processing of rRNA and strains carrying this allele are viable, but impaired in mRNA decay. In contrast, the rne1 mutation does not seem to inhibit degradosome formation, but at non-permissive temperature, the catalytic activity of RNaseE is abolished (Coburn et al., 1999). The endonucleolytic cleavage of sodB mRNA was observed and no increase of sodB-lacZ expression was found in an rnc rne 1 double mutant at non-permissive temperature. This suggests that, rather than the catalytic activity of RNaseE, the interaction between other major components of the degradosome is important.

Fur-dependent RNA stabilization did not fully account for the activation of $s o d B$ expression, suggesting that an additional effect, at the transcriptional level, may be mediated by Fur. A Fur-dependent transcriptional effect mediated by H-NS was effectively observed. (i) The 
effect of H-NS is not post-transcriptional because hns mutation in the fur strain did not increase $s o d B$ mRNA decay, whereas sodB-lacZ expression was increased (two to three times). (ii) The effect of H-NS is probably indirect because examination of the $\operatorname{sod} B$ promoter region revealed no putative curved DNA region, specific for recognition by H-NS. (iii) There was no cumulative effect of H-NS and RNA stabilization by inactivation of the major RNases (RNaseIII and RNaseE). This suggests a common Fur-regulated pathway leading to transcriptional and post-transcriptional effects. The numerous bands observed upon the gradual cooling of the psodB RNA region suggested that this RNA may take up numerous conformations. It is possible that all Fur-dependent effects, transcriptional and posttranscriptional, may be mediated by a single intermediate regulator. We speculate that the expression of the gene encoding the intermediate regulatory protein ' $\mathrm{X}$ ' is probably negatively regulated by Fur and positively by H-NS. Only if Fur repression was relieved, could H-NS activate transcription. H-NS is known to be a transcriptional repressor, but two-dimensional protein gel analysis has shown that the expression of many genes is activated by H-NS, although the underlying mechanism is unclear. It has also been demonstrated that $\mathrm{H}$ NS-mediated repression can be eliminated by inducing target-gene expression (reviewed by Atlung \& Ingmer, 1997). These findings are consistent with our hypothesis: an ' $\mathrm{X}$ ' target gene may be repressed by Fur and activated by H-NS if Fur repression is relieved.

Few proteins have been shown to bind both DNA and RNA (Shamoo et al., 1993). Such binding may account for the transcriptional and post-transcriptional effects of the putative ' $\mathrm{X}$ ' protein. We favour a model in which the ' $\mathrm{X}$ ' protein binds to DNA in the region between the transcription and translation start sites, slowing down the progression of RNA polymerase, generating two effects : reduction of the efficiency of $s o d B$ transcription and formation of RNA structures more accessible to endonucleolytic cleavage. Experiments are under way to determine whether such a model of coupling between DNA transcription and RNA stabilization, consistent with several of the observations reported in this work, operates in reality.

\section{ACKNOWLEDGEMENTS}

We thank G. Micheli for studying the curvature of the $\operatorname{sodB}$ promoter region with the 3D-WEDGE program. We thank I. Michaud-Soret for providing purified Fur, and P. Régnier and M. Springer for helpful advice on our work and critical reading of the manuscript. S. Dubrac was supported by a grant from la Fondation pour la Recherche Médicale. This work was supported by a grant from the Association pour la Recherche sur le Cancer (no. 5581).

\section{REFERENCES}

Alén, C. \& Sonenshein, A. L. (1999). Bacillus subtilis aconitase is an RNA-binding protein. Proc Natl Acad Sci USA 96, 10412-10417.
Andrews, S. C., Harrison, P. M. \& Guest, J. R. (1989). Cloning, sequencing, and mapping of the bacterioferritin gene $(b f r)$ of Escherichia coli. J Bacteriol 171, 3940-3947.

Atlung, T. \& Ingmer, H. (1997). H-NS: a modulator of environmentally regulated gene expression. Mol Microbiol 24, 7-17.

Babitzke, P., Granger, L., Olszewski, J. \& Kushner, S. R. (1993). Analysis of mRNA decay and rRNA processing in Escherichia coli multiple mutants carrying a deletion in RNase III. J Bacteriol 175, 229-239.

Babst, M., Hennecke, H. \& Fischer, H.-M. (1996). Two different mechanisms are involved in the heat-shock regulation of chaperonin gene expression in Bradyrhizobium japonicum. J Mol Biol 19, 827-839.

Bagg, A. \& Neilands, J. B. (1987). Molecular mechanism of regulation of siderophore-mediated iron assimilation. Microbiol Rev 51, 509-518.

Calderwood, S. B. \& Mekalanos, J. J. (1988). Confirmation of the Fur operator site by insertion of a synthetic oligonucleotide into an operon fusion plasmid. J Bacteriol 170, 1015-1017.

Cesarone, C. F., Bolognesi, C. \& Santi, L. (1979). Improved microfluorometric DNA determination in biological material using 33258 Hoechst. Anal Biochem 100, 188-197.

Coburn, G. A., Miao, X., Briant, D. J. \& Mackie, G. A. (1999). Reconstitution of a minimal RNA degradosome demonstrates functional coordination between a 3' exonuclease and a DEADbox RNA helicase. Genes and Dev 13, 2594-2603.

Compan, I. \& Touati, D. (1993). Interaction of six global transcription regulators in expression of manganese superoxide dismutase in Escherichia coli K-12. J Bacteriol 175, 1687-1696.

Dieckmann, S. \& Wang, J. C. (1985). On the sequence determinants and flexibility of the kinetoplast DNA fragment with abnormal gel electrophoretic mobilities. J Mol Biol 186, 1-11.

Dubrac, S. \& Touati, D. (2000). Fur positive regulation of iron superoxide dismutase in Escherichia coli: functional analysis of the $\operatorname{sodB}$ promoter. J Bacteriol 182, 3802-3808.

Escolar, L., de Lorenzo, V. \& Perez-Martin, J. (1997). Metalloregulation in vitro of the aerobactin promoter of Escherichia coli by the Fur (ferric uptake regulation) protein. Mol Microbiol 26, 799-808.

Escolar, L., Perez-Martin, J. \& de Lorenzo, V. (1998). Binding of the Fur (Ferric Uptake Regulator) repressor of Escherichia coli to arrays of the GATAAT sequence. J Mol Biol 283, 537-547.

Escolar, L., Perez-Martin, J. \& de Lorenzo, V. (1999). Opening the iron box: transcriptional metalloregulation by the Fur protein. $J$ Bacteriol 181, 6223-6229.

Fridovich, I. (1997). Superoxide anion radical $\left(\mathrm{O}_{2}^{-}\right)$, superoxide dismutases (SODs), and related matters. J Biol Chem 272, 18515-18517.

Gruer, M. J. \& Guest, J. R. (1994). Two genetically distinct and differentially regulated aconitases (AcnA and $A c n B$ ) in Escherichia coli. Microbiology 140, 2531-2541.

Hajnsdorf, E., Carpousis, A. J. \& Régnier, P. (1994). Nucleolytic inactivation and degradation of the RNase III processed $p n p$ message encoding polynucleotide phosphorylase of Escherichia coli. J Mol Biol 239, 439-454.

Hall, H. K. \& Foster, J. W. (1996). The role of Fur in the acid tolerance response of Salmonella typhimurium is physiologically and genetically separable from its role in iron acquisition. $J$ Bacteriol 178, 5683-5691.

Halliwell, B. \& Gutteridge, M. C. (1984). Oxygen toxicity, oxygen radicals, transition metals and disease. Biochem J 219, 1-14. 
Hantke, K. (2001). Iron and metal regulation in bacteria. Curr Opin Microbiol 4, 172-177.

Keyer, K. \& Imlay, J. A. (1996). Superoxide accelerates DNA damage by elevating free-iron levels. Proc Natl Acad Sci U S A 93, 13635-13640.

Laurent-Winter, C., Ngo, S., Danchin, A. \& Bertin, P. (1997). Role of Escherichia coli histone-like nucleoid-structuring protein in bacterial metabolism and stress response. Eur J Biochem 244, 767-773.

Lopez, P. J., Marchand, I., Joyce, S. A. \& Dreyfus, M. (1999). The C-terminal half of RNase E, which organizes the Escherichia coli degradosome, participates in mRNA degradation but not rRNA processing in vivo. Mol Microbiol 33, 188-199.

de Lorenzo, V., Giovannini, F., Herrero, M. \& Neilands, J. B. (1988). Metal ion regulation of gene expression. Mol Biol 203, 875-884.

de Lorenzo, V., Wee, S., Herrero, M. \& Neilands, J. B. (1987). Operator sequences of the aerobactin operon of plasmid ColV-K3 binding the ferric uptake regulation (fur) repressor. J Bacteriol 169, 2624-2630.

Mackie, G. A. (1998). Ribonuclease $\mathrm{E}$ is a $5^{\prime}$-end-dependent endonuclease. Nature 395, 720-723.

Miller, J. H. (1992). A Short Course in Bacterial Genetics. Cold Spring Harbor, NY: Cold Spring Harbor Laboratory.

Mudd, E. A., Krisch, H. M. \& Higgins, C. F. (1990). RNase E, an endoribonuclease, has a general role in the chemical decay of Escherichia coli mRNA: evidence that rne and ams are the same genetic locus. Mol Microbiol 4, 2127-2135.

Nicholson, A. W. (1999). Function, mechanism and regulation of bacterial ribonucleases. FEMS 23, 371-390.

Niederhoffer, E. C., Naranjo, C. M., Bradley, K. L. \& Fee, J. A. (1990). Control of Escherichia coli superoxide dismutase $(\operatorname{sod} A$ and $\operatorname{sod} B$ ) genes by the ferric iron uptake regulation (Fur) locus. J Bacteriol 172, 1930-1938.

Ohta, T., Ueguchi, C. \& Mizuno, T. (1999). rpoS function is essential for $b g l$ silencing caused by C-terminal truncated H-NS in Escherichia coli. J Bacteriol 181, 6278-6283.

Sakamoto, H. \& Touati, D. (1984). Cloning of the iron superoxide dismutase gene $(\operatorname{sod} B)$ in Escherichia coli K12. J Bacteriol 159, 418-420.
Sambrook, J., Fritsch, E. F. \& Maniatis, T. (1989). Molecular Cloning: a Laboratory Manual, 2nd edn. Cold Spring Harbor, NY : Cold Spring Harbor Laboratory.

Shamoo, Y., Tam, A., Konigsberg, W. H. \& Williams, K. R. (1993). Translational repression by the bacteriophage $\mathrm{T} 4$ gene 32 protein involves specific recognition of an RNA pseudoknot structure. $J$ Mol Biol 232, 89-104.

Stojiljkovic, I., Baumler, J. A. \& Hantke, K. (1994). Fur regulon in gram-negative bacteria. J Mol Biol 236, 531-545.

Tardat, B. \& Touati, D. (1991). Two global regulators repress the anaerobic expression of MnSOD in E. coli: Fur (ferric uptake regulation) and Arc (aerobic respiration control). Mol Microbiol 5, 455-465.

Tardat, B. \& Touati, D. (1993). Iron and oxygen regulation of Escherichia coli MnSOD expression: competition between the global regulators Fur and ArcA for binding to DNA. Mol Microbiol 9, 53-63.

Touati, D. (1997). Superoxide dismutases in bacteria and pathogen protists. In Oxidative Stress and the Molecular Biology of Antioxidant Defenses, pp. 447-493. Edited by J. Scandalios. Cold Spring Harbor, NY: Cold Spring Harbor Laboratory.

Touati, D. (2000). Iron and oxidative stress in bacteria. Arch Biochem Biophys 373, 1-6.

Uzan, M., Favre, R. \& Brody, E. (1988). A nuclease that cuts specifically in the ribosome binding site of some T4 mRNAs. Proc Natl Acad Sci U S A 85, 8895-8899.

Wee, S., Neilands, J. B., Bittner, M. L., Hemming, B. C., Haymore, B. L. \& Seetharam, R. (1988). Expression, isolation and properties of Fur (ferric uptake regulation) protein of Escherichia coli K12. Biol Metals 1, 62-68.

Yamada, H., Yoshida, T., Tnaka, K.-I., Sasakawa, C. \& Mizuno, T. (1991). Molecular analysis of the Escherichia coli hns gene encoding a DNA binding protein, which preferentially recognizes curved DNA sequence. Mol Gen Genet 230, 332-336.

Zheng, M., Doan, B., Schneider, T. D. \& Storz, G. (1999). OxyR and SoxRS regulation of fur. J Bacteriol 181, 4639-4643.

Received 26 June 2001; revised 3 September 2001; accepted 7 September 2001. 